\title{
Disseminated zoster in an adult patient with extensive burns: a case report
}

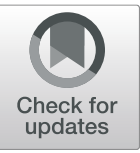

Yoshitaka Kubota1*, Kentaro Kosaka', Toshinori Hokazono², Yoshihisa Yamaji ', Takafumi Tezuka', Shinsuke Akita', Motone Kuriyama' and Nobuyuki Mitsukawa' ${ }^{1}$

\begin{abstract}
Background: Shingles (localized zoster) and disseminated zoster are caused by the reactivation of latent varicella zoster virus (VZV). Reactivation of VZV is related to impaired cell-mediated immunity. Extensive burns affecting a patient result in burn-related immunosuppression and cytokine storm. Despite immunosuppression in burn patients, the reactivation of VZV is extremely rare, whereas eczema herpeticum, caused by reactivation of latent herpes simplex virus (HSV), is common. We have found only 1 published case of VZV reactivation during burn treatment in the literature.
\end{abstract}

Case presentation: A 51-year-old man was burned in a fire, which affected $60 \%$ of his total body surface area (TBSA), and also received inhalation injury (day 0). Despite fluid resuscitation, he showed persistent renal failure. Continuous hemodialysis and filtration (CHDF) combined with polymyxin B-immobilized fiber column direct hemoperfusion (PMX-DHP) therapy was used for cytokine modulation. Autologous and allogeneic skin grafting was performed. On day 15, multiple-drug-resistant Pseudomonas aeruginosa (MDRP) was detected from a blood specimen, and the patient developed multiple organ failure (MOF). On day 31, compact aggregations of small vesicles appeared on the intact skin of his left knee and left buttock. The vesicles were located within the 4th lumbar (L4) spinal dermatome. From day 32 to day 34, similar new vesicles arose on his intact skin and epithelializing skin-graft donor sites. We diagnosed disseminated zoster, based on the patient's age, the characteristic occurrence of the initial vesicles within a limited area of intact skin in the left L4 dermatome, and a positive Tzank smear. Serologic testing on day 36 showed a high level of anti-VZV immunoglobulin (lg)G with low levels of anti-VZV IgM, anti-HSV IgG, and anti-HSV IgM. The patient was isolated in a negative-pressure room to avoid air-borne spread of VZV. On day 52, the patient died.

Conclusions: To the best of our knowledge, our patient is the second case of reactivation of VZV during burn treatment. It is unclear why reactivation of VZV is rare in patients with burn-related immunosuppression, whereas HSV reactivation is common. Cytokine modulation throughout the treatment period using CHDF combined with PMX-DHP might have been related to the rare reactivation of VZV in our patient. Our case provides an additional information on the relationship between the immune status of a patient with extensive burns and reactivation of latent VZV or HSV.

Keywords: Burn, Varicella zoster virus, Herpes simplex virus, Reactivation, Air-borne infection, Hemodialysis

\footnotetext{
*Correspondence: kbkt@hospital.chiba-u.jp; kubota-cbu@umin.ac.jp

'Department of Plastic Surgery, Chiba University, 1-8-1, Inohana, Chuo-ku,

Chiba-city, Chiba \#260-8677, Japan

Full list of author information is available at the end of the article
}

(c) The Author(s). 2019 Open Access This article is distributed under the terms of the Creative Commons Attribution 4.0 International License (http://creativecommons.org/licenses/by/4.0/), which permits unrestricted use, distribution, and reproduction in any medium, provided you give appropriate credit to the original author(s) and the source, provide a link to the Creative Commons license, and indicate if changes were made. The Creative Commons Public Domain Dedication waiver (http://creativecommons.org/publicdomain/zero/1.0/) applies to the data made available in this article, unless otherwise stated. 


\section{Background}

Disseminated zoster, caused by the reactivation of latent varicella zoster virus (VZV), is sometimes seen in patients with immunocompromised status, such as post-organ transplantation, lymphoma, and acquired immunodeficiency syndrome (AIDS) [1]. Extensive burns affecting a patient result in burn-related immunosuppression and cytokine storm. Despite immunosuppression in burn patients, the reactivation of VZV is extremely rare, whereas eczema herpeticum, also known as Kaposi's varicelliform eruption (KVE), caused by reactivation of latent herpes simplex virus (HSV) is common. To the best of our knowledge, only 1 case of VZV reactivation during burn treatment can be found in the literature [2]. Herein, we report a burn patient who developed disseminated zoster as a complication of burn treatment, which required airborne infection isolation.

\section{Case presentation}

A 51-year-old unemployed Asian man sustained a thermal burn affecting $60 \%$ of his total body surface area (TBSA) in a gasoline fire. He arrived at our hospital $4 \mathrm{~h}$ after injury (day 0). Upon initial examination, he was in shock and found to have inhalation injury. He had third degree burns on his face, head, neck, chest, back, bilateral upper extremities, abdomen, and bilateral thighs. Fluid resuscitation and artificial ventilation with tracheal intubation were started. According to his family, he did not have any obvious comorbidities. The patient's history of VZV vaccination and VZV infection were unknown. Despite fluid resuscitation and catecholamine support, he had persistent oliguria and hypotension. Continuous hemodialysis and filtration (CHDF) combined with polymyxin B-immobilized fiber column direct hemoperfusion (PMX-DHP) was started on day 1 to treat his renal failure, reduce cytokine storm, and remove endotoxins in an attempt to prevent development of multiple organ failure (MOF). Multiple eschar debridements and autologous and allogeneic skin grafting were performed. Almost complete escharectomy was achieved by day 13 . However, throughout the treatment period, the patient's general condition remained critical. He could not be weaned from artificial ventilation and CHDF, and he continuously needed catecholamine circulatory support. On day 10, he developed cardiac arrest that was treated by cardiac massage and intravenous adrenaline, with return of spontaneous circulation (ROSC).

Engraftment of skin grafts and epithelialization of the skin donor sites were poor, and on day 15, multiple-drug-resistant Pseudomonas aeruginosa (MDRP) was detected in specimens from his burn wound and blood. His burn sepsis was refractory to treatment, and he developed multiple organ failure (MOF). On day 31, compact aggregations of small vesicles appeared on the intact skin of his left knee and left buttock. The vesicles were located within the 4th lumbar (L4) spinal dermatome (Fig. 1). From day 32 to day 34, similar new vesicles arose on his intact skin and epithelializing split-thickness skin graft harvested sites on both legs, both knees, entire abdomen, both buttocks, and entire face and neck. The vesicles ruptured sequentially and became multiple skin ulcers. On day 34, the patient was evaluated by dermatologists, and was diagnosed with disseminated zoster caused by reactivation of latent

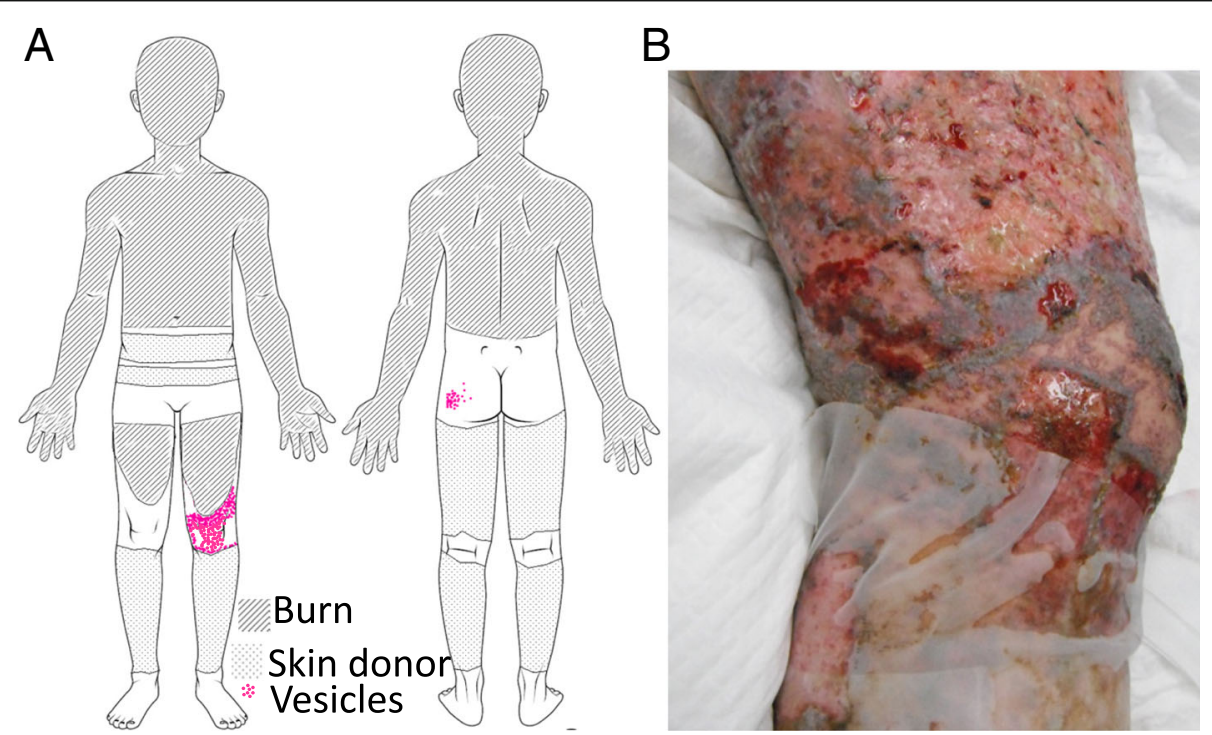

Fig. 1 Vesicles at onset of eruption on day 31. a Distribution of vesicles on day 31. Aggregated vesicles were seen on intact skin of the left knee and left buttock along in the fourth lumbar nerve root (L4) dermatome. b Photograph of the left knee on day 31 . Aggregated vesicles on the intact skin of the left knee 
varicella zoster virus (VZV), based on the patient's age, characteristic pattern of aggregations of vesicles initially limited to the left L4 dermatome, and positive Tzank smear (Giemsa-stained vesicular content positive for multinucleated giant cells). Because disseminated zoster can be transmitted via an airborne route, the patient was isolated in a negative-pressure room to avoid airborne spread of VZV. On day 36, the patient's serum levels of anti-VZV immunoglobulin (Ig) G, anti-VZV IgM, anti-HSV IgG, and anti-HSV IgM antibodies were measured by enzyme-linked immunosorbent assay (ELISA) kits (Denka Seiken, Tokyo, Japan). The antigen in the measuring kits of anti-VZV IgG and anti-VZV IgM is isolated from Vero cells infected with VZV HS strain. The antigen in the measuring kits of anti-HSV IgG and anti-HSV IgM is isolated from RD cells infected with HSV H-S1 strain. The antibody titers calculated from a standard curve using ELISA OD values. The results showed a high anti-VZV IgG antibody titer of 128 (> 4.0 is defined as positive according to the manufacturer's insert) and low anti-VZV IgM antibody titer of 0.46 $(<0.8$ defined as negative by the manufacturer's insert). The anti-HSV IgG antibody titer was indeterminant at 2.5 (> 4, positive; <2.0, negative; 2.0-3.9, indeterminant by the manufacturer's insert), and the anti-HSV IgM antibody titer was negative at $0.47(<0.8$ defined as negative by the manufacturer's insert). Intravenous acyclovir, $500 \mathrm{mg}$ daily, was started. Despite intensive care and acyclovir for 14 days, the patient's general condition worsened. On day 48, most vesicles had not healed and had become skin ulcers (Fig. 2), and not much skin was available skin for skin grafts. Therefore, treating the burn was impossible. On day 52, the patient died of multiple organ failure. No cases of VZV infection occurred in other ICU patients or ICU personnel during the treatment period.

\section{Discussion and conclusions}

Herein, we reported an adult case of extensive burn injury complicated by a generalized vesicular eruption that was suspected of being disseminated zoster due to reactivation of latent VZV. Disseminated zoster during burn treatment is extremely rare [2]. To the best of our knowledge, our case is the second case of reactivation of VZV during the burn treatment. Disseminated zoster that occurs before burn injuries heal severely limits the treatment of burns because of reduced amounts of intact skin for skin grafts. Moreover, VZV infection can involve many organs, including the lungs, heart, liver, and kidneys; and thus in our case it might have accelerated the course of pre-existing multiple MOF that had developed prior to VZV reactivation because of hypotension, inhalation injury, and MDRP infection. In addition,

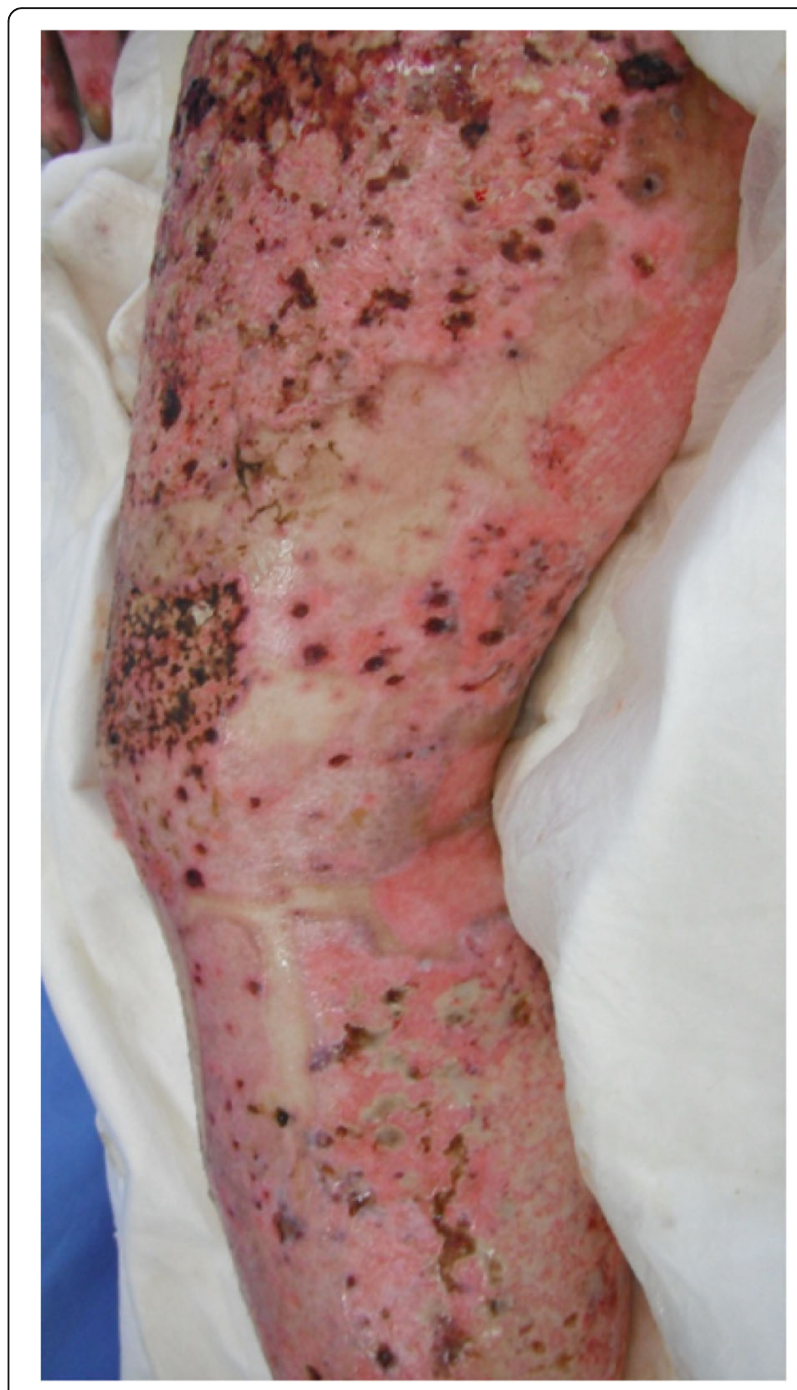

Fig. 2 Vesicles on day 48. Ulcers resulting from unhealed vesicles on right thigh, knee, and leg

disseminated zoster leads to the problem of nosocomial airborne VZV infection.

VZV is a DNA virus and a member of the human herpes virus (HHV) family, which consists of 8 known types of viruses [3]. Varicella, also known as chickenpox, is the clinical manifestation of the initial VZV infection. Subsequently, VZV remains latent in the trigeminal and dorsal root ganglia. Localized zoster, also known as shingles, is the clinical manifestation of the reactivation of latent VZV $[4,5]$. The reactivation of VZV is triggered by a weakened immune system. In most cases, the reactivation of VZV results in shingles, which can occur even in healthy individuals. In shingles, aggregations of vesicles appear unilaterally in a single dermatome or several adjacent dermatomes. The systemic involvement of other organs is rarely seen in shingles. By contrast, in disseminated zoster, a rare manifestation of reactivated 
latent VZV, the systemic distribution of vesicular eruptions and systemic dissemination of the pathogen to many other organs occurs. Disseminated zoster is rarely seen in immunocompetent patients, but has been reported in immunocompromised patients such as those who have undergone hematopoietic stem cell transplantation and solid organ transplantation, or who have lymphoma or acquired immune deficiency syndrome (AIDS) [6].

Patients with extensive burns have burn-related immunosuppression $[7,8]$. However, reports on the reactivation of latent VZV manifesting as either shingles or disseminated zoster in burn patients are rare. The reasons that reactivation of latent VZV is rare in burn patients are unclear $[2,9,10]$. VZV involvement in burn patients is typically seen as varicella in pediatric burn patients who are negative for prior VZV infection or have not been vaccinated [11]. Varicella outbreaks among pediatric burn patients and other patients in the ICU have been reported [12]. Sheridan et al. reported that the incidence of varicella in a pediatric burn unit was $0.1 \%$ (12 of 8869 patients) [13]. However, to the best of our knowledge, there have only been 3 reported cases of shingles related to burn treatment (Table 1) $[2,14,15]$. Among those cases only 1 case of shingles occurred before the burn wounds were healed. The patient was an 81-year-old woman with a $12 \% \mathrm{TBSA}$ burn on her legs who, 46 days after sustaining a burn injury, developed a vesicular exanthem on the intact skin of her right forehead and eyelids, consistent with the dermatome of the first division of the trigeminal nerve. VZV was confirmed by isolation of the virus and elevated titers of complement-fixation antibody [2]. To the best of our knowledge, there are no reports of disseminated zoster occurring during burn treatment.

HSV, a member of the HHV family, is also associated with the occurrence of herpetic lesions in burn patients. HSV includes HSV types 1 (HSV-1) and 2 (HSV-2) and is transmitted by direct contact. Primary infection of HSV or reactivation of latent HSV can result in herpetic skin or mucous membrane lesions. Typically, oral lesions are due to HSV-1 and genital lesions to HSV-2. In burn patients, herpetic lesions associated with HSV are likely to occur in second degree burns and split-thickness skin graft (STSG) harvested sites during the healing process [16-18]. Disseminated herpetic lesions due to HSV are called KVEs and are also known as eczema herpeticum. In the literature, KVEs are more common than latent VZV reactivation in burn patients. A preceding abnormal skin condition is more important as a cause of KVEs than in seen for shingles or disseminated zoster. Therefore, KVE occurs in preceding lesions associated with skin diseases such as atopic dermatitis, psoriasis, contact dermatitis, and burns [19]. Varicella and KVEs in burn patients are likely to involve burned skin in the healing process, which indicates an association between epithelial cell proliferation and viral activity.

Sometimes differentiating between KVEs, varicella, and disseminated zoster is difficult. In our case, a dermatologist examined the patient and diagnosed disseminated zoster 3 days after the onset of the eruptions. The diagnosis of disseminated zoster was made based on the age of the patient, the primary onset of exanthema on the skin of the left L4 dermatome, aggregated pattern of vesicular eruptions, vesicles appearing on normal skin rather than involving healing burn lesions or STSG

Table 1 Reactivation of varicella zoster virus (VZV) related to burn treatment

\begin{tabular}{|c|c|c|c|c|c|c|c|c|}
\hline Authors & $\begin{array}{l}\text { Age } \\
\text { (year) }\end{array}$ & Gender & $\begin{array}{l}\text { Immunostatus } \\
\text { before burn injury }\end{array}$ & $\begin{array}{l}\text { Extent of Burn } \\
\left(\% \mathrm{TBSA}^{\mathrm{a}}\right)\end{array}$ & $\begin{array}{l}\text { Onset after } \\
\text { burn injury }\end{array}$ & Site & VZV confirmation & Outcome \\
\hline $\begin{array}{l}\text { Matthews } \\
\text { et al., } 1979\end{array}$ & 81 & Female & Immunocompetent & $12 \%$ TBSA & $\begin{array}{l}46 \text { days (During } \\
\text { burn treatment) }\end{array}$ & $\begin{array}{l}\text { Intact skin of the } \\
\text { face (Dermatome } \\
\text { of right 1st branch } \\
\text { of trigeminal nerve) }\end{array}$ & $\begin{array}{l}\text { Serological, clinical, } \\
\text { electron microscopy, } \\
\text { and culture }\end{array}$ & Healed \\
\hline $\begin{array}{l}\text { Lin and Cinat, } \\
2010\end{array}$ & 29 & Male & Immunocompetent & 4\%TBSA & $\begin{array}{l}2.5 \text { years (After } \\
\text { burn wound } \\
\text { was healed) }\end{array}$ & $\begin{array}{l}\text { Healed skin graft } \\
\text { on right ankle }\end{array}$ & Serological and clinical & $\begin{array}{l}\text { Loss of } \\
\text { skin graft }\end{array}$ \\
\hline $\begin{array}{l}\text { Kikuchi and } \\
\text { Isa, } 1976\end{array}$ & 70 & Female & Immunocompetent & $\begin{array}{l}\text { Less than } \\
1 \% \text { TBSA }\end{array}$ & $\begin{array}{l}3.5 \text { years (After } \\
\text { burn wound } \\
\text { was healed) }\end{array}$ & $\begin{array}{l}\text { Healed skin graft } \\
\text { on right back }\end{array}$ & $\begin{array}{l}\text { Clinical (age, distribution } \\
\text { of vesicles on right chest, } \\
\text { right back, and right arm.) }\end{array}$ & Healed \\
\hline Our case & 51 & Male & Immunocompetent & $60 \%$ TBSA & $\begin{array}{l}31 \text { days (During } \\
\text { burn treatment) }\end{array}$ & $\begin{array}{l}\text { First, intact skin } \\
\text { of left knee and } \\
\text { left buttock (L4 } \\
\text { dermatome). Then, } \\
\text { disseminated. }\end{array}$ & $\begin{array}{l}\text { Serological and clinical } \\
\text { (age, distribution } \\
\text { of primary vesicular } \\
\text { exanthem, aggregated } \\
\text { style of vesicles, several } \\
\text { days of continually } \\
\text { erupting rashes, concurrent } \\
\text { presence of vesicles, } \\
\text { pustules, and crusts.) }\end{array}$ & Dead \\
\hline
\end{tabular}


donor sites, asynchronous generalized eruption of vesicles, and concomitant existence of vesicles, pustules, and crusts. Those findings all support the diagnosis of disseminated zoster instead of varicella or KVE. Serologic testing performed 5 days after the onset of vesicular eruptions also supported the diagnosis of disseminated zoster. However, completely denying the possibility of HSV involvement in our case is difficult, because the simultaneous involvement of HSV and VZV has been reported. Giehl et al. reported that in $1.8 \%$ of patients in whom the clinically suspected pathogen was VZV, an additional HSV infection was identified by polymerase chain reaction (PCR) [20]. Although Giehl et al.'s data showed that there are cases of simultaneous involvement of HSV and VZV, they also showed that a clinical diagnosis of zoster, in which suspected pathogen was VZV, based only on clinical manifestations is highly accurate, that was confirmed by PCR. Clinically, there is a need for diagnosing disseminated zoster rapidly in order to prevent nosocomial infection due to potential airborne spread of VZV, whereas HSV in KVEs does not spread by an airborne route.

The first-line treatment of disseminated zoster is acyclovir, which is also true for shingles, varicella, and HSV infection. VZV infection of immunocompromised patients is life-threatening, and early high-dose acyclovir has been reported [21]. In our case, the patient was undergoing 24-h CHDF, which corresponded to $10 \mathrm{~mL} /$ $\mathrm{min} / 1.73 \mathrm{~m}^{2}$ of creatinine clearance [22]. A consensus protocol for acyclovir treatment of patients with renal failure in Japan recommends daily intravenous administration of $250 \mathrm{mg}$ of acyclovir. We administered $500 \mathrm{mg}$ of acyclovir as high-dose acyclovir therapy. Intravenous immunoglobulin has also been reported to be a treatment option $[6,10]$. VZV vaccination cannot be used as a preventative in immunocompromised patients, because the VZV vaccine is a live-virus vaccine. A fatal case of disseminated zoster occurring after VZV vaccination of an immunocompromised patient was reported [23].

The molecular trigger of the reactivation of latent VZV is unknown. However, it is clear that deficient cell-mediated immunity in elderly and immunocompromised patients is associated with the reactivation of latent VZV [3]. Immunosuppression is common in patients with extensive burn injuries. The reason why reactivation of latent VZV is rare in burn patients in contrast to the frequent reactivation of HSV remains unclear [2]. Although both VZV and HSV are members of the HHV family and demonstrate similar clinical manifestations, VZV and HSV are different with respect to viral molecular function: e.g., VZV expresses multiple open-reading-frame (ORF) proteins and immediate early proteins during latency, whereas HSV expresses a latency-associated-transcript (LAT) without protein synthesis during latency [3, 24]. Differences between the molecular mechanisms of the reactivation of latent VZV and HSV may be key in accounting for the difference between the incidence rates of disseminated zoster and KVEs in burn patients.

Fever itself is one of the stimulations that promote HSV reactivation. Warren et al. reported that in $46 \%$ (190 of 411) of patients undergone artificially induced fever, oral-labial herpes whose cause is thought to be reactivation of HSV occurred, whereas no herpes zoster by reactivation of VZV were observed [25]. Fever commonly seen during burn treatment may be one of the reasons for common HSV reactivation in opposite to rare VZV reactivation.

Nerve growth factor (NGF) and epidermal growth factor (EGF) inhibits HSV reactivation in neuron in vitro $[26,27]$. Both NGF and EGF are increasing in skin during healing process after burn injury $[28,29]$. We think that the elevated demand for NGF and EGF in the skin after burn injury may lead to decreased levels of NGF and EGF in ganglia, that can promote HSV reactivation in ganglia.

In severely burned patient, the number of $\mathrm{CD} 8+\mathrm{T}$ cells decreases [30]. Cytolytic CD8+ T cells exist around latent HSV-1 infected ganglia neurons, whereas no cytolytic CD8 $+\mathrm{T}$ cells exist around latent VZV infected ganglia neurons [31]. Cytolytic CD8 + T cells are thought to suppress $\mathrm{HSV}-1$ reactivation without causing neural damage. In contrast, cytolytic CD8+ T cells may have no role in suppression of VZV reactivation. HSV-1 presents viral antigen by MHC class I molecules in latently infected neuron, and HSV-1 specific CD8+ T cell interact with HSV-1 latent neuron [32]. On the other hand, VZV downregulates cell surface MHC class I expression. Interaction between latently VZV infected neuron and VZV specific CD8+ T cell may not play a major role in controlling VZV reactivation. Thus, we think that the reduction of $\mathrm{CD} 8+\mathrm{T}$ cells in severely burn patient may lead to reactivation of HSV but not VZV.

In contrast to the reduction of the number of $\mathrm{T}$ cells in severely burn patient, the number of B cells do not alter after burn injury [33]. B cells and antibody production is crucial for preventing some kind of viral reactivation in central nerve system in mice [34]. We think that similar mechanism may exist in VZV latently infected ganglia.

The rate of cytomegalovirus (CMV) infection is considerably high in severely burned patients, that $71 \%$ in CMV seropositive burn patients and 13\% in CMV seronegative patients [35]. Superinfection with CMV on latent HSV infected human cell provokes HSV reactivation in vitro, whereas VZV reactivation cannot be provoked by CMV superinfection [36]. We think CMV superinfection may play an important role 
in commonness of HSV reactivation and rarity of VZV reactivation in burn patients.

VZV infects not only neurons but also many other cell types. In severe systemic cases of VZV infection, infected cells can be found in almost every organ, including the spleen, liver, lungs, thymus, digestive tract, kidneys, pancreas, aorta, heart, and brain [1, 3, 6, 3742]. The VZV organisms in disseminated zoster are thought to be spread through the blood stream [43]. In our case, liver and respiratory dysfunction were evident. However, determining if the dysfunctions were due disseminated zoster or many other burn-related underlying conditions such as MDRP infection, circulatory insufficiency, or systemic inflammation was difficult.

CHDF blood purification combined with PMX-DHP might have been associated with the occurrence of disseminated zoster in our case. CHDF plus PMX-DHP was initiated on day 1 and continued until the day the patient died (day 52). CHDF plus PMX-DHP was used not only to treat renal failure, but also to modulate inflammatory cytokines such as tumor necrosis factor-alpha (TNF- $\alpha$ ), interleukin (IL)-1, and IL-6 [22]. Extensive burn injury broadly impairs the functional components of the immune system: e.g., including the function of phagocytes and dendric cells, T-cell homeostasis, immune signaling, and gene expression $[7,8,44$, 45]. In addition, renal failure alone suppresses T-cell functioning and reduces cell-mediated immunity [46]. Although the effects of long-term cytokine modulation by CHDF plus PMX-DHP in patients with extensive burn injuries are unknown, these interventions might activate VZV by an unknown mechanism.

The prevention of airborne transmission of VZV to other patients and health care workers is clinically important. The reported incidence rate of disseminated zoster is lower than the incidence rate of KVE in burn patients. However, there is a possibility that disseminated zoster in burn patients is overlooked, because disseminated zoster has been rarely known to occur as a complication in burn patients. Varicella outbreaks among pediatric burn patients and other ICU patients have been reported [11, 12]. Anugulruengkitt et al. reported that the prevalence of VZV non-immune healthcare workers was $2.6 \%$ [47]. In our hospital, all healthcare workers are checked for the presence of anti-VZV IgG antibody when they start working, and the results are stored in an online database. Associated with our case, no healthcare workers without immunity to VZV were identified. Patients who were in the ICU during the period spanning the eruption of vesicles on day 31 to when the patient was transferred to the negative-pressure isolation room were tested for anti-VZV IgG antibody. Fortunately, patients without immunity to VZV were not found.
In conclusion, we treated a severely burned patient with suspected disseminated zoster basing on his clinical findings and results of serology. Immediate isolation of the patient in a negative-pressure room was implemented to prevent airborne infections of VZV. Burn-related immunosuppression and long-term cytokine modulation by CHDF plus PMX-DHP might lead to rare, fatal reactivation of latent VZV infection.

\begin{abstract}
Abbreviations
AIDS: Acquired immunodeficiency syndrome; CHDF: Continuous hemodialysis and filtration; ELISA: Enzyme-linked immunosorbent assay; HHV: Human herpes virus; HSV: Herpes simplex virus; Ig: Immunoglobulin; IL: Interleukin; KVE: Kaposi's varicelliform eruption; L4: 4th lumbar; LAT: Latency-associated-transcript; MDRP: Multiple-drug-resistant Pseudomonas aeruginosa; MOF: Multiple organ failure; ORF: Open-readingframe; PCR: Polymerase chain reaction; PMX-DHP: Polymyxin B-immobilized fiber column direct hemoperfusion; ROSC: Return of spontaneous circulation; STSG: Split-thickness skin graft; TBSA: Total body surface area; TNF-a: Tumor necrosis factor-alpha; VZV: Varicella zoster virus
\end{abstract}

\section{Acknowledgements}

We the authors are thankful to Center for Advanced Medicine of Chiba University Hospital for image processing.

\section{Funding}

None.

Availability of data and materials

Blood test data is available upon request.

\section{Authors' contributions}

$Y K, T H$, and NM designed the research and drafted the manuscript. $Y Y, T$, and SA interpreted the data. KK and MK researched the related literatures and performed scientific overview of our case. All authors read and approved the final manuscript.

Ethics approval and consent to participate

This study was conducted in accordance with the ethical committee of Chiba University School of Medicine (approval number 1673). All studies were performed according to the guidelines of the Declaration of Helsinki.

\section{Consent for publication}

Written informed consent was obtained from the patient and his family for publication of this case report and the accompanying images. A copy of the written consent is available for review by the Editor-in-Chief.

\section{Competing interests}

The authors declare that they have no competing interest.

\section{Publisher's Note}

Springer Nature remains neutral with regard to jurisdictional claims in published maps and institutional affiliations.

\section{Author details}

'Department of Plastic Surgery, Chiba University, 1-8-1, Inohana, Chuo-ku, Chiba-city, Chiba \#260-8677, Japan. ${ }^{2}$ Department of Plastic Surgery, Imakiire General Hospital, 4-16, Shimotatsuo-cho, Kagoshima-city, Kagoshima \#892-0852, Japan.

Received: 21 March 2019 Accepted: 16 May 2019 Published online: 23 May 2019

\section{References}

1. Yamada N, Sanada Y, Okada N, Wakiya T, Ihara Y, Urahashi T, Mizuta K. Successful rescue of disseminated varicella infection with multiple organ failure in a pediatric living donor liver transplant recipient: a case report and literature review. Virol J. 2015;12:91. 
2. Matthews SCW, Levick PL, Coombes EJ, Ely DW, Pead PJ, Saeed AA. Viral infections in a group of burned patients. Burns. 1979;6:55-60.

3. Zerboni L, Sen N, Oliver SL, Arvin AM. Molecular mechanisms of varicella zoster virus pathogenesis. Nat Rev Microbiol. 2014;12:197-210.

4. Gilden DH, Vafai A, Shtram Y, Becker Y, Devlin M, Wellish M. Varicella-zoster virus DNA in human sensory ganglia. Nature. 1983;306:478-80.

5. Lungu O, Annunziato PW, Gershon A, Staugaitis SM, Josefson D, LaRussa P, Silverstein SJ. Reactivated and latent varicella-zoster virus in human dorsal root ganglia. Proc Natl Acad Sci U S A. 1995;92:10980-4.

6. Hagiya H, Kimura M, Miyamoto T, Otsuka F. Systemic varicella-zoster virus infection in two critically ill patients in an intensive care unit. Virol J. 2013;10:225.

7. Rice TC, Armocida SM, Kuethe JW, Midura EF, Jain A, Hildeman DA, Healy $D P$, Gulbins $E$, Caldwell CC. Burn injury influences the T cell homeostasis in a butyrate-acid sphingomyelinase dependent manner. Cell Immunol. 2017; 313:25-31.

8. Hansbrough JF, Field TO, Jr., Gadd MA, Soderberg C. Immune response modulation after burn injury: T cells and antibodies. J Burn Care Rehabil. 1987:8:509-12.

9. Hayden FG, Himel HN, Heggers JP. Herpesvirus infections in burn patients. Chest. 1994;106:15S-21S discussion 34S-35S.

10. Wurzer P, Guillory A, Parvizi D, Clayton RP, Branski LK, Kamolz LP, Finnerty CC, Herndon DN, Lee JO. Human herpes viruses in burn patients: a systematic review. Burns. 2017:43:25-33.

11. Weintraub WH, Lilly JR, Randolph JG. A chickenpox epidemic in a pediatric burn unit. Surgery. 1974;76:490-4.

12. Gustafson TL, Lavely GB, Brawner ER Jr, Hutcheson RH Jr, Wright PF, Schaffner W. An outbreak of airborne nosocomial varicella. Pediatrics. 1982;70:550-6.

13. Sheridan RL, Weber JM, Pasternak MM, Mulligan JM, Tompkins RG. A 15-year experience with varicella infections in a pediatric burn unit. Burns. 1999;25:353-6.

14. Lin $\mathrm{P}$, Cinat $\mathrm{M}$. Herpes zoster involving a skin graft. J Burn Care Res. 2010;31:813-5.

15. Kikuchi I, Isa F. Herpes zoster involving a skin graft. Br J Plast Surg. 1976;29:245-6.

16. Brandt SJ, Tribble CG, Lakeman AD, Hayden FG. Herpes simplex burn wound infections: epidemiology of a case cluster and responses to acyclovir therapy. Surgery. 1985;98:338-43.

17. Bartralot R, Garcia-Patos V, Rodriguez-Cano L, Castells A. Kaposi's varicelliform eruption in a patient with healing second degree burns. Clin Exp Dermatol. 1996;21:127-30.

18. Nishimura M, Maekawa M, Hino Y, Mihara K, Kohda H. Kaposi's varicelliform eruption. Development in a patient with a healing second-degree burn. Arch Dermatol. 1984;120:799-800.

19. Sohail M, Khan FA, Shami HB, Bashir MM. Management of eczema herpeticum in a burn unit. J Pak Med Assoc. 2016;66:1357-61.

20. Giehl KA, Muller-Sander E, Rottenkolber M, Degitz K, Volkenandt M, Berking C. Identification and characterization of 20 immunocompetent patients with simultaneous varicella zoster and herpes simplex virus infection. J Eur Acad Dermatol Venereol. 2008;22:722-8.

21. Fehr T, Bossart W, Wahl C, Binswanger U. Disseminated varicella infection in adult renal allograft recipients: four cases and a review of the literature. Transplantation. 2002;73:608-11.

22. Hirasawa H, Sugai T, Ohtake Y, Oda S, Matsuda K, Kitamura N. Blood purification for prevention and treatment of multiple organ failure. World Surg. 1996;20:482-6.

23. Costa E, Buxton J, Brown J, Templeton KE, Breuer J, Johannessen I. Fatal disseminated varicella zoster infection following zoster vaccination in an immunocompromised patient. BMJ Case Rep. 2016;2016.

24. Kennedy PG, Rovnak J, Badani H, Cohrs RJ. A comparison of herpes simplex virus type 1 and varicella-zoster virus latency and reactivation. J Gen Virol. 2015;96:1581-602.

25. Warren SL, Carpenter CM, Boak RA. Symptomatic herpes, a sequela of artificially induced fever : incidence and c aspects; recovery of a virus from herpetic vesicles, and comparison with a k strain of herpes virus. J Exp Med. 1940;71:155-68.

26. Wilcox CL, Smith RL, Freed CR, Johnson EM Jr. Nerve growth factordependence of herpes simplex virus latency in peripheral sympathetic and sensory neurons in vitro. J Neurosci. 1990;10:1268-75.

27. Du T, Zhou G, Roizman B. Induction of apoptosis accelerates reactivation of latent HSV-1 in ganglionic organ cultures and replication in cell cultures. Proc Natl Acad Sci U S A. 2012;109:14616-21.
28. Jurjus A, Hourani R, Daouk H, Youssef L, Bou-Khalil P, Haidar H, Atiyeh B, Saade N. Effect of denervation on burn wound healing. Ann Burns Fire Disasters. 2018;31:278-91.

29. Wenczak BA, Lynch JB, Nanney LB. Epidermal growth factor receptor distribution in burn wounds. Implications for growth factor-mediated repair. J Clin Invest. 1992;90:2392-401.

30. Maldonado MD, Venturoli A, Franco A, Nunez-Roldan A. Specific changes in peripheral blood lymphocyte phenotype from burn patients. Probable origin of the thermal injury-related lymphocytopenia. Burns. 1991;17:188-92.

31. Verjans GM, Hintzen RQ, van Dun JM, Poot A, Milikan JC, Laman JD, Langerak AW, Kinchington PR, Osterhaus AD. Selective retention of herpes simplex virus-specific T cells in latently infected human trigeminal ganglia. Proc Natl Acad Sci U S A. 2007:104:3496-501.

32. Pereira RA, Tscharke DC, Simmons A. Upregulation of class I major histocompatibility complex gene expression in primary sensory neurons, satellite cells, and Schwann cells of mice in response to acute but not latent herpes simplex virus infection in vivo. J Exp Med. 1994;180:841-50.

33. Munster AM, Eurenius K, Katz RM, Canales L, Foley FD, Mortensen RF. Cellmediated immunity after thermal injury. Ann Surg. 1973;177:139-43.

34. Ramakrishna C, Stohlman SA, Atkinson RD, Shlomchik MJ, Bergmann CC. Mechanisms of central nervous system viral persistence: the critical role of antibody and B cells. J Immunol. 2002;168:1204-11.

35. Bordes J, Maslin J, Prunet B, d'Aranda E, Lacroix G, Goutorbe P, Dantzer $E$, Meaudre E. Cytomegalovirus infection in severe burn patients monitoring by real-time polymerase chain reaction: a prospective study. Burns. 2011;37:434-9.

36. Shiraki K, Rapp F. Establishment of herpes simplex virus latency in vitro with cycloheximide. J Gen Virol. 1986;67 ( Pt 11:2497-500.

37. Badani H, White T, Schulick N, Raeburn CD, Topkaya I, Gilden D, Nagel MA. Frequency of varicella zoster virus DNA in human adrenal glands. J NeuroOncol. 2016;22:400-2.

38. Plisek S, Pliskova L, Bostik V, Prasil P, Laco J, Chlibek R, Vyroubal P, Kosina P, Bostik P. Fulminant hepatitis and death associated with disseminated varicella in an immunocompromised adult from the Czech Republic caused by a wild-type clade 4 varicella-zoster virus strain. J Clin Virol. 2011;50:72-5.

39. Leung J, Broder KR, Marin M. Severe varicella in persons vaccinated with varicella vaccine (breakthrough varicella): a systematic literature review. Expert Rev Vaccines. 2017;16:391-400.

40. Miliauskas JR, Webber BL. Disseminated varicella at autopsy in children with cancer. Cancer. 1984;53:1518-25.

41. Ioannou A, Tsappa I, Metaxa S, Missouris CG. Ventricular fibrillation following varicella zoster myocarditis. Case Rep Cardiol. 2017;2017:1017686.

42. Gilden D, White T, Boyer PJ, Galetta KM, Hedley-Whyte ET, Frank M, Holmes D, Nagel MA. Varicella zoster virus infection in granulomatous arteritis of the aorta. J Infect Dis. 2016;213:1866-71.

43. Kimura H, Kido S, Ozaki T, Tanaka N, Ito Y, Williams RK, Morishima T. Comparison of quantitations of viral load in varicella and zoster. J Clin Microbiol. 2000;38:2447-9.

44. D'Arpa N, Accardo-Palumbo A, Amato G, D'Amelio L, Pileri D, Cataldo V, Mogavero R, Lombardo C, Napoli B, Conte F. Circulating dendritic cells following burn. Burns. 2009;35:513-8.

45. Moore CB, Medina MA, van Deventer HW, O'Connor BP, Cameron S, Taxman DJ, Maile R, Ting JP, Cairns BA. Downregulation of immune signaling genes in patients with large surface burn injury. J Burn Care Res. 2007;28:879-87.

46. Hussein MM, Mooij JM, Roujouleh H. Tuberculosis and chronic renal disease. Semin Dial. 2003;16:38-44.

47. Anugulruengkitt $S$, Puthanakit T, Siengboon S, Paitoonpong $L$, Kowitdamrong E, Pancharoen C, Pichitchok Y. Prevalence and characteristics of pediatric healthcare workers without immunity to varicella zoster virus. Jpn J Infect Dis. 2017;70:216-8. 